DOI https://doi.org/10.46845/2541-8254-2021-4(31)-2-2

УДК 316

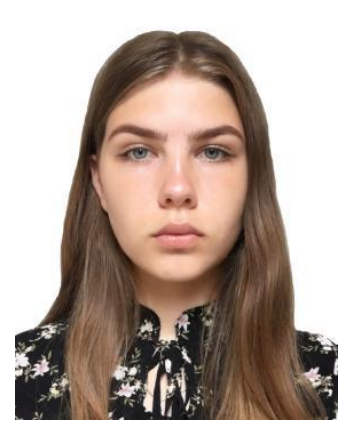

\title{
ВЛИЯНИЕ СРЕДСТВ МАССОВОЙ ИНФОРМАЦИИ НА ФОРМИРОВАНИЕ ЦЕННОСТНЫХ ОРИЕНТАЦИЙ КАЛИНИНГРАДСКОЙ СТУДЕНЧЕСКОЙ МОЛОДЕЖИ
}

\author{
М.В. Борисова, студентка 1 курса \\ e-mail: manyutta@mail.ru \\ ФГБОУ ВО «Калининградский государственный \\ технический университет» \\ Н.Н. Ярыгин, д-р филос. наук, доц., \\ e-mail: nikolaj.yarygin @klgtu.ru \\ ФГБОУ ВО «Калининградский государственный \\ технический университет»
}

В статье анализируется влияние средств массовой информации на формирование ценностных ориентаций калининградской студенческой молодежи. Объектом данного исследования явились студенты дневной формы обучения. Целью поискового социологического исследования стало выявление влияния различных средств массовой информации на формирование ценностных ориентаций среди студенческой молодежи. Поставлены следующие задачи: определение объекта исследования, составление анкеты с вопросами, проведение опроса в интернете, анализ результатов исследования. Для подбора респондентов использован метод доступной выборки. Результаты проведенного исследования говорят о том, что самым влиятельным источником информации для студентов являются социальные сети, а самыми непопулярными названы радио, телевидение и печатная пресса. Полученные результаты говорят о том, что студенческую молодежь интересует в первую очередь диалог разных точек зрения на происходящие события, возможность их самостоятельного анализа. Данным критериям отвечают именно социальные сети.

\begin{abstract}
Ключевые слова: средства массовой информации, студенческая молодежь, соииальные сети
\end{abstract}

\section{ВВЕДЕНИЕ}

В информационном обществе средства массовой информации приобретают все большее значение. Особенно это стало заметно в период пандемии COVID-19, когда высшие учебные заведения вынуждены были перейти на удаленную форму обучения. Студенческая молодежь, в первую очередь первокурсники, практически лишилась привычного процесса социализации на новом этапе своего жизненного пути. Старшекурсники хотя бы имели опыт предыдущего прямого общения между собой, тогда как первокурсники еще не познакомились друг с другом. Поэтому последним пришлось проходить этот процесс онлайн посредством социальных сетей. Таким образом, по предположению авторов, именно социальные сети сегодня стали самым популярным источником информации для студенческой молодежи. Для проверки данной гипотезы и восполнения научного пробела авторы решили провести исследование, поскольку подобных работ о Калининградском регионе в условиях текущей пандемии не обнаружено. Можно назвать лишь некоторые публикации последнего времени, посвященные молодежной тематике: А.А. Желнина, В.А. Смирнов, И.Л. Мерзлякова, А.А. Линченко, Э.В. Овчинникова [1-3]. О растущей роли 
Интернета в транзитивном мире как источника новой информации, механизма социализации современной молодежи пишут Т.Д. Марцинковская и С.В. Преображенская $[4,5]$.

\section{ОБЬЕКТ ИССЛЕДОВАНИЯ}

Объектом поискового социологического исследования авторы определили студентов калининградских вузов дневной формы обучения. Наибольшее количество опрошенных приходится на Калининградский государственный технический университет, есть также учащиеся Балтийского федерального университета имени Им. Канта.

\section{ЦЕЛЬ И ЗАДАЧИ ИССЛЕДОВАНИЯ}

Целью исследования является определение популярности средств массовой информации среди калининградской студенческой молодежи. Для достижения этой цели сформулированы следующие задачи: определение объекта исследования, составление опросной анкеты, проведение опроса в интернете, анализ результатов проделанной работы.

\section{МЕТОДЫ ИССЛЕДОВАНИЯ}

Объектом изучения выступает калининградская студенческая молодежь дневной формы обучения, насчитывающая порядка 20 тыс. человек, что является генеральной совокупностью поискового социологического исследования [6, с. 103]. Главным методом сбора данных служил анкетный интернет-опрос, также использовалось наблюдение за отношением студентов к средствам массовой информации. Выборочная совокупность, то есть доля генеральной совокупности, которая подлежала непосредственному опросу, представляет собой 65 студентов. Респонденты выбраны методом доступных выборок, которые «...заведомо не являются репрезентативными, но требуют минимальных затрат. В отдельных случаях, когда генеральная совокупность отличается очень высокой степенью однородности, ...результаты исследования могут оказаться приемлемыми» [7, с. 193]. При данном методе опрашиваются любые представители генеральной совокупности, a студенческую среду в данном случае можно считать вполне гомогенной. Доступные выборки наиболее часто используются в исследованиях аудитории СМИ непосредственно через СМИ с помощью публикуемых в печатных СМИ анкет, интерактивных опросов по радио, телевидению, в Интернете и т.п. [7, с. 193]. Опрос проведен на платформе Google, в группах социальной сети «ВКонтакте» посредством рассылки анкет калининградским студентам.

\section{РЕЗУЛЬТАТЫ ИССЛЕДОВАНИЯ}

В ходе опроса и наблюдения выявлены количественные и качественные характеристики калининградских студентов, говорящие об их отношении к средствам массовой информации, ценностных ориентациях и предпочтениях.

Результаты первых двух вопросов свидетельствуют о том, что большая часть опрошенных являются студентами Калининградского государственного технического университета.

Вопрос 3 позволил узнать, что основными источниками информации для студентов являются социальные сети (60 человек) и новостные агентства в Интернете (34 человека). Данное положение подтверждается также исследованиями Т.Д. Марцинковской и C.B. Преображенской, проведенными в период текущей пандемии COVID-19. В частности они пишут: «...можно констатировать постоянное увеличение влияния Интернета, который становится средством не только общения, но и получения новой информации, а также важным фактором структурирования образа мира у молодежи» [4, с. 45-46].

Вопрос 4 показывает, что студенты чаще доверяют информации, полученной из вышеуказанных источников, чем нет (46 человек).

Вопросы 5 и 6 авторы считают основополагающими, так как именно от усвоения студентами транслируемых ценностей зависит влияние СМИ. Опрос показал, что для 
студентов на первом месте находится семья (50 человек), на втором - любовь, дружба и саморазвитие (44 человека) и на третьем - карьера (38 человек).
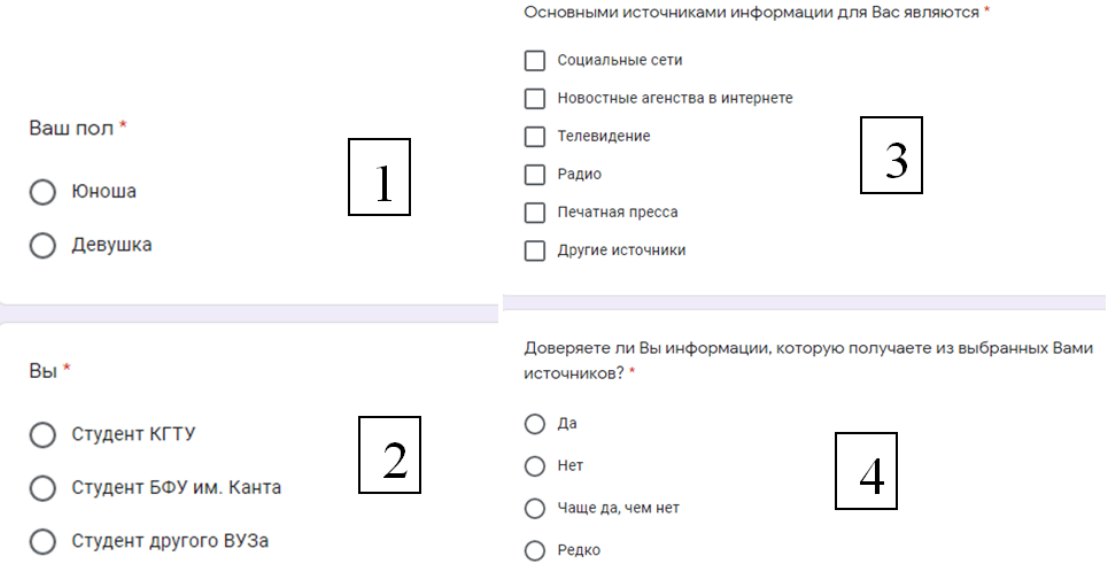

Какие жизненные ценности Вы сиитаете для себя более важными? :

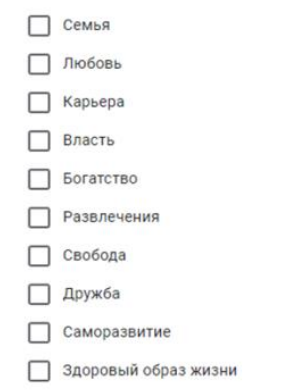

Какое СмИ, по Вашему мнению, оказывает позитиеное влияние на студенческую молодежь? *

$\square$ социальные сети

$\square$ новостные агенства в интернете

$\square$ телевидение

$\square$ радио

$\square$ Печатная пресса

$\square$ другие источники

$\square$ ни один из выше перечисленных

Как, по Вашему мнению, СмИ влияют на жизнь студенческой молодежи? *

$\square$ помогают ориентироваться в море информации

$\square$ позволяют узнавать о происходящих в мире событиях

$\square$ служат только для развлечения

$\square$ отнимают много времени

$\square$ содержат большое количество ненужной информации, которая запоминается

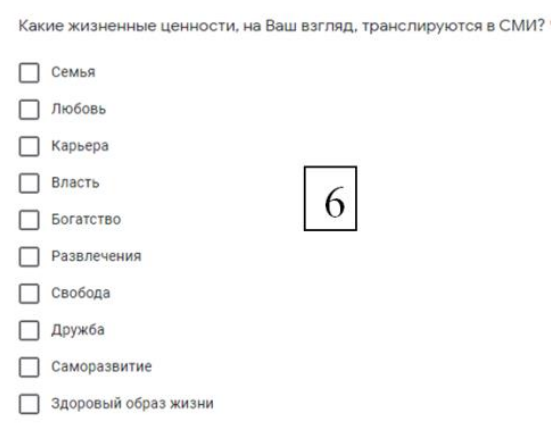

Какое СМИ, по Вашему мнению, оказывает негативное влияние на студенческую моподежь? *

$\square$ социальные сети

$\square$ новостные агенства в интернете

$\square$ телевидение

$\square$ Радио

$\square$ печатная пресса

$\square$ другие источники

$\square$ ни один из вышеперечисленных

Какие из данных факторов, по Вашему мнению, помогают СМИ оказывать влияние на студенческую молодежь?

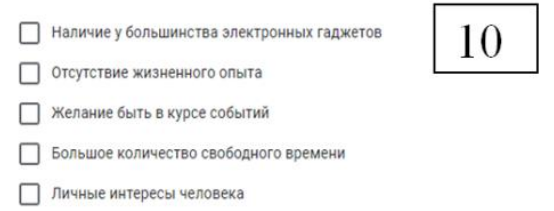

Рисунок 1 - Анкета, которая использовалась при опросе

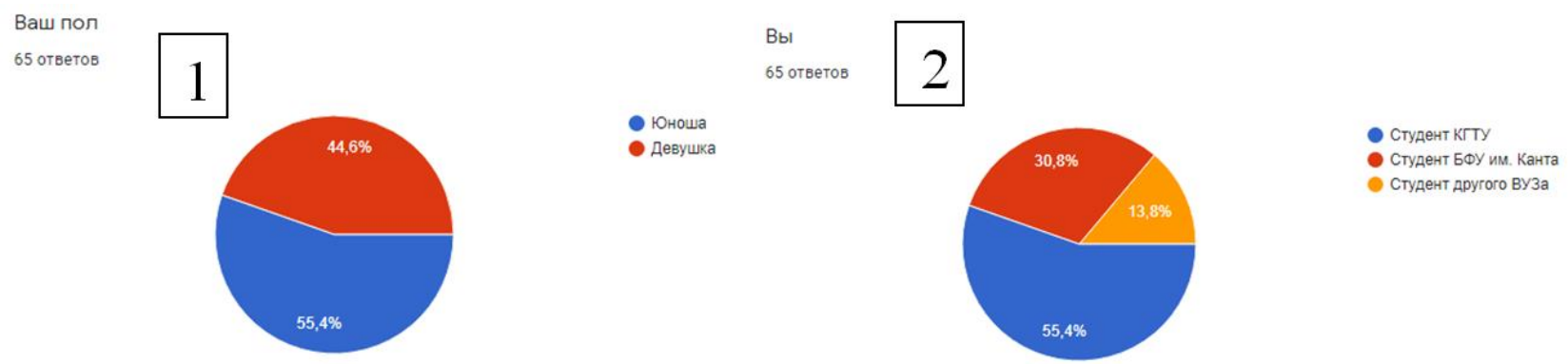

Рисунок 2 - Демографическая характеристика респондентов 
Основными источниками информации для Вас являются

65 ответов

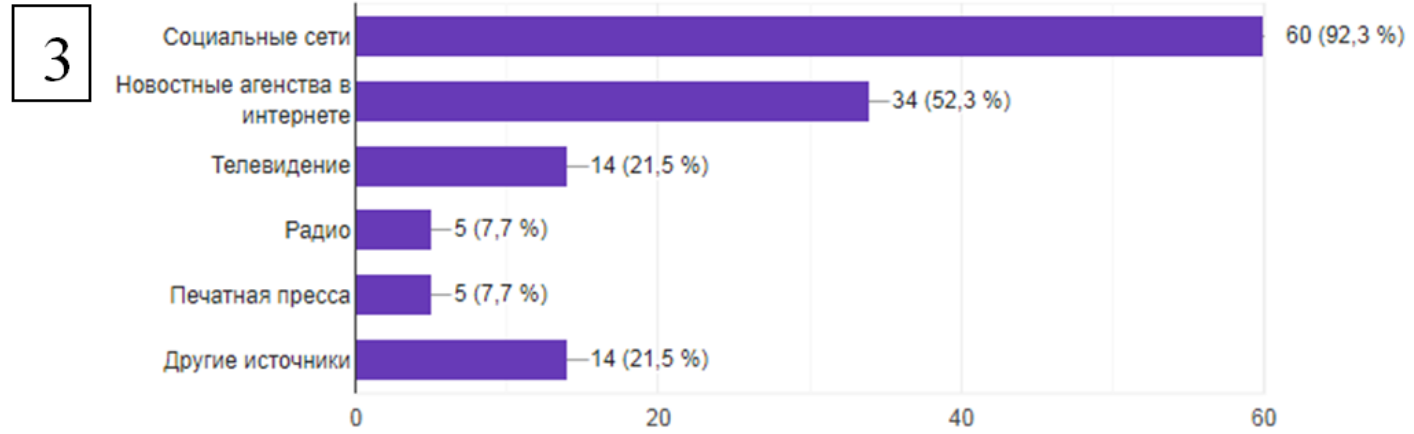

Рисунок 3 - Основные источники информачии для респондентов

Доверяете ли Вы информации, которую получаете из выбранных Вами источников?

65 ответов
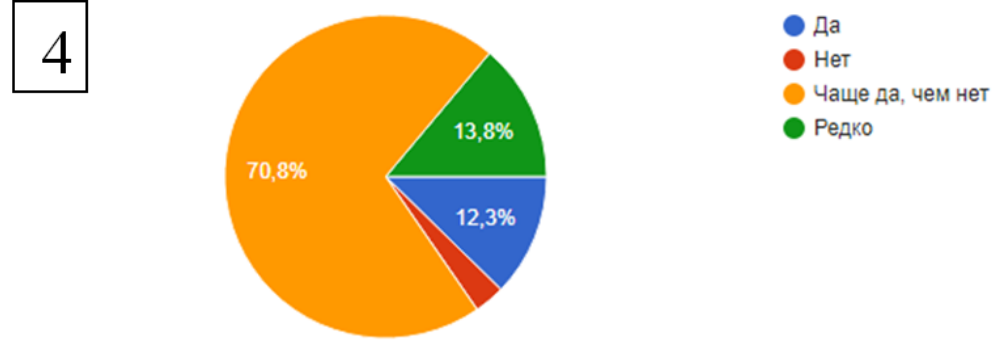

Рисунок 4 - Степень доверия к источникам информации, выбранных респондентами

Какие жизненные ценности Вы считаете для себя более важными?

65 ответов

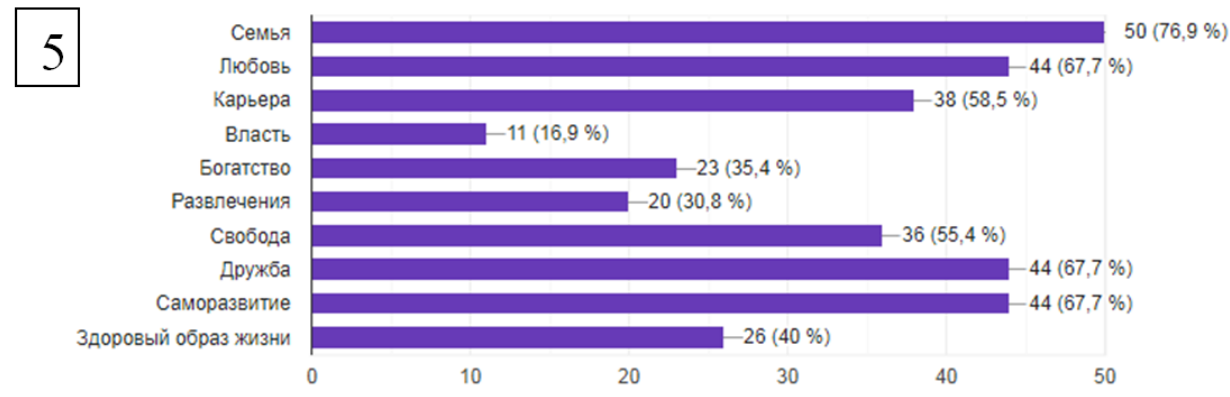

Рисунок 5 - Жизненные ценности респондентов

Транслируемые СМИ ценности сильно отличаются от установок студентов, так как на первое место в этом случае поставлены власть (49 человек), на второе - карьера (36 человек) и на третье - богатство (34 человека).

Как можно заметить, основные интересы и ценности студентов, такие как дружба, любовь, саморазвитие и семья, почти не транслируются в СМИ. Это говорит о том, что по большому счету СМИ не отвечают на запросы студенческой молодежи.

В вопросах 7 и 8 студенты оценили источники информации по характеру влияния. Самым позитивно влияющим источником являются социальные сети (45 голосов). Самым негативно действующим источником студенты назвали телевидение (47 голосов).

В вопросе 9 студенты выделили основные сферы деятельности СМИ, которые оказывают влияние на молодежь. По мнению студентов, СМИ оказывают более позитивное 
влияние, чем негативное, позволяют узнавать происходящие в мире события. За этот вариант проголосовало 55 человек.

В вопросе 10 респонденты выделили основные факторы, которые позволяют оказывать влияние СМИ на студенческую молодежь. По мнению студентов, наличие у большинства электронных гаджетов является основным фактором влияния СМИ, этот вариант подтвердили 49 человек.

Какие жизненные ценности, на Ваш взгляд, транслируются в СМИ?

65 ответов

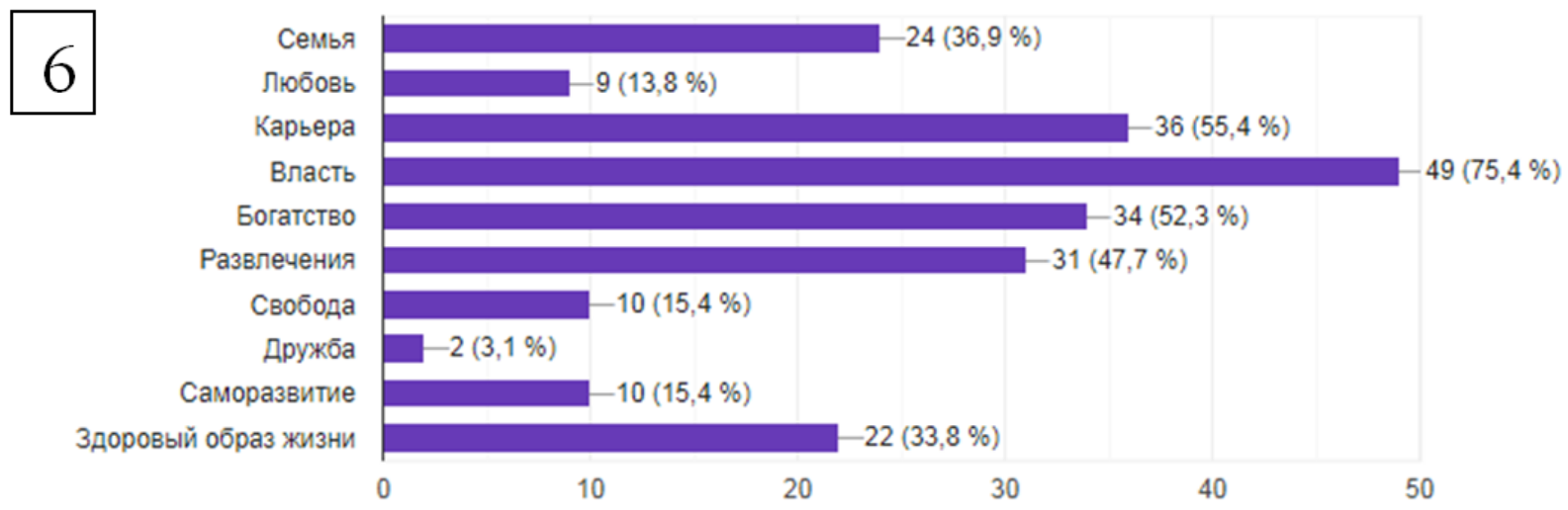

Рисунок 6 - Жизненные иенности, транслируемые СМИ

Какое СМИ, по Вашему мнению, оказывает позитивное влияние на студенческую молодежь?

65 ответов

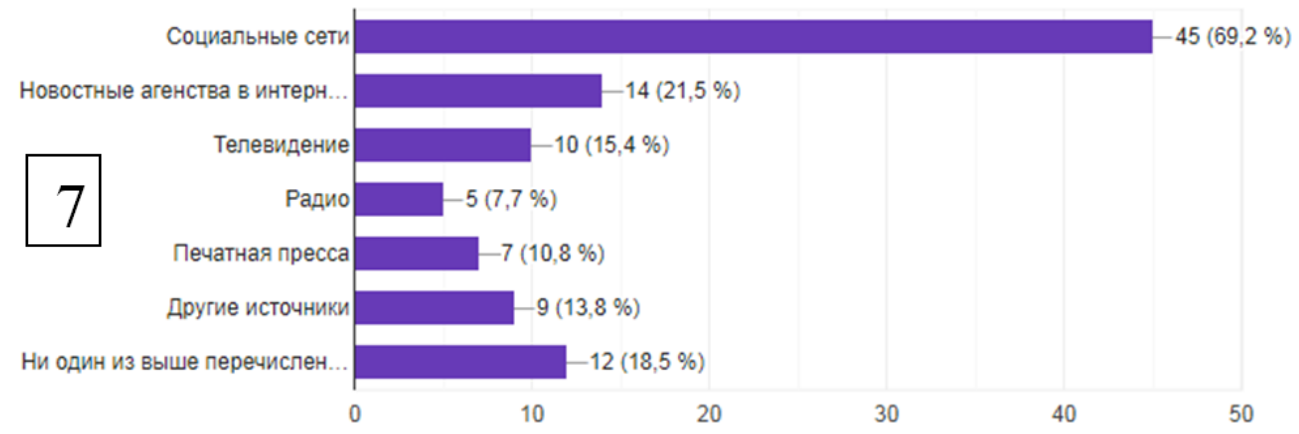

Рисунок 7 - Характер влияния СМИ

Какое СМИ, по Вашему мнению, оказывает негативное влияние на студенческую молодежь?

65 ответов

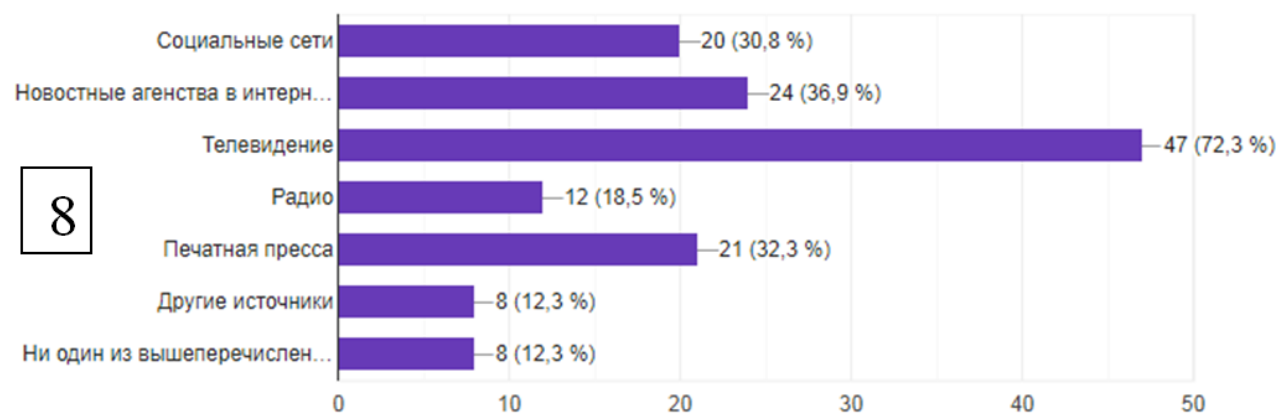

Рисунок 8 - Как СМИ влияет на жизнь студентов 


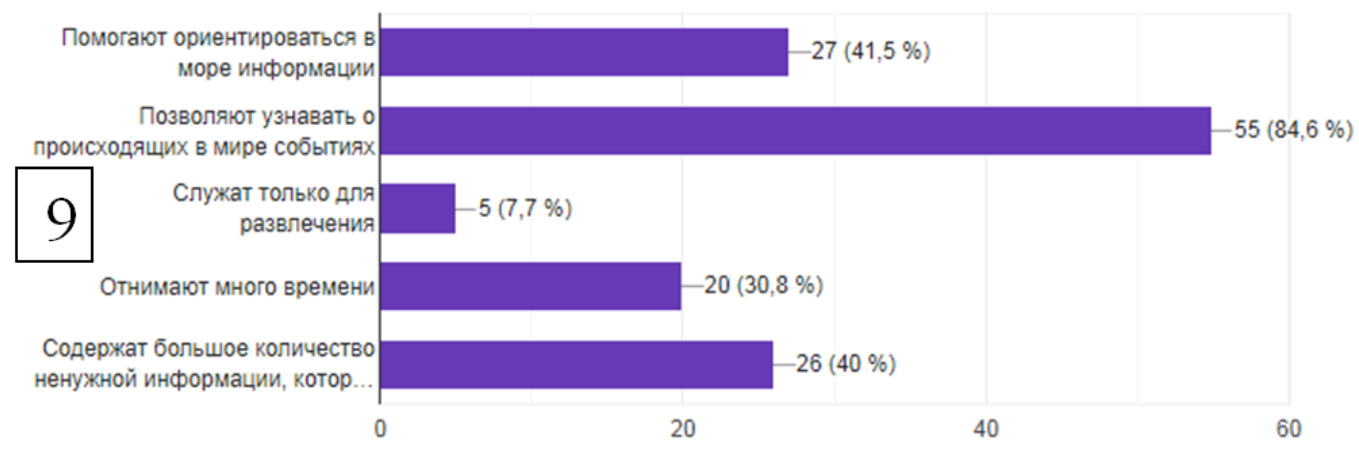

Рисунок 9- Влияние СМИ на молодежь

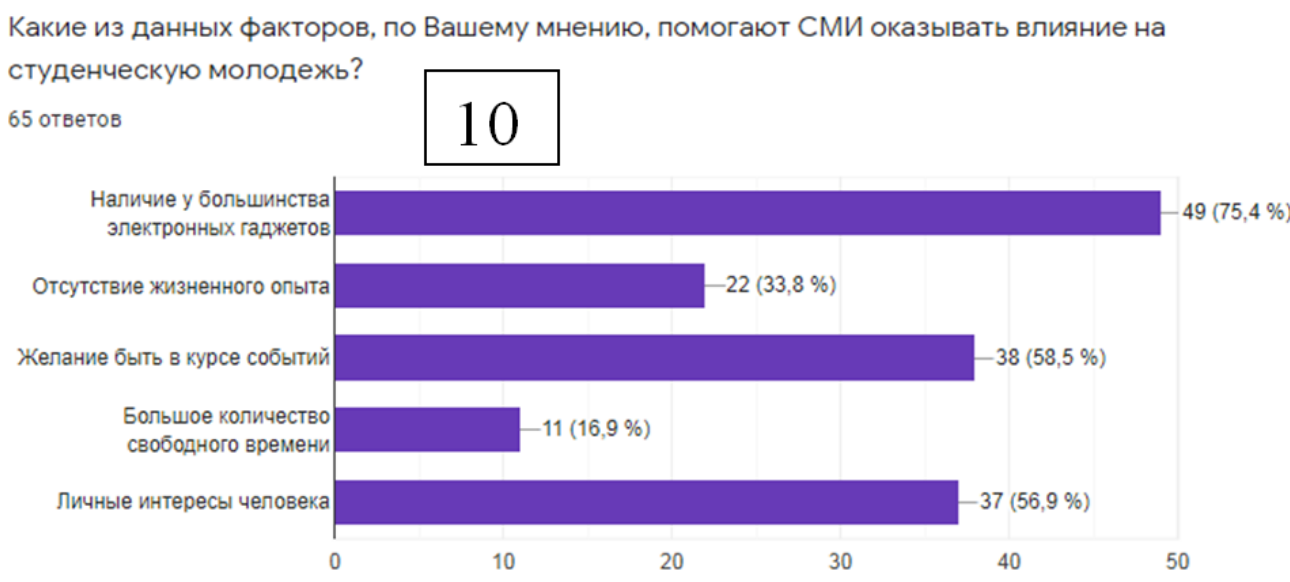

Рисунок 10 - Факторы влияния СМИ

\section{ЗАКЛЮЧЕНИЕ}

В итоге получается, что основным источником информации в условиях текущей пандемии COVID-19 для калининградских студентов являются социальные сети и новостные агентства в Интернете. Данные явления сегодня теснят привычные формы социализации студенческой молодежи. Ценности, транслируемые через официальные СМИ не совпадают со студенческими, поэтому студенты считают, что отрицательное влияние оказывает больше телевидение, нежели социальные сети. В последних больше свободы, многообразия и вариативности, значит, есть место для самых разных мнений, возможность развития критического мышления, самостоятельного анализа происходящих в мире явлений. По мнению студентов, Интернет-СМИ помогают самостоятельно разбираться в новых событиях, в свежих новостях и ориентироваться в большом потоке информации. Наличие электронных гаджетов у большинства студентов, желание узнавать новое, а так же их личные интересы позволяют Интернет-СМИ оказывать заметное положительное влияние на студенческую молодежь.

\section{СПИСОК ЛИТЕРАТУРЫ}

1. Желнина, А.А. «Политтусовка» - альтернативное публичное пространство в сфере молодежной политики / А.А. Желнина // Социс. Социологические исследования. - 2014. № 3. - С. $80-88$.

2. Смирнов, В.А. Молодежная политика: опыт системного описания / В.А. Смирнов // Социс. Социологические исследования. - 2014. - № 3. - С. 72-80.

3. Мерзлякова, И.Л. Об историческом сознании современной студенческой молодежи / И.Л. Мерзлякова, А.А. Линченко, Э.В. Овчинникова // Социс. Социологические исследования. - 2014. - № 12. - С. 89-96. 
4. Марцинковская, Т.Д. Информационная социализация студентов в транзитивном мире / Т.Д. Марцинковская, С.В. Преображенская // Вопросы психологии. - 2020. - Т. 66, № 3. - С. 45-55.

5. Марцинковская, Т.Д. Личностные границы пространства и времени в состоянии депривации COVID-19 / Т.Д. Марцинковская // Вопросы психологии. - 2020. - Т. 66, № 4. С. 104-113.

6. Ядов, В.А. Стратегия социологического исследования. Описание, объяснение, понимание социальной реальности / В.А. Ядов; 3-е изд., испр. - Москва: Омега-Л, 2009. $567 \mathrm{c}$.

7. Терещенко, О.В. Выборка доступная // Новейший социологический словарь / сост. А.А. Грицанов, В.Л. Абушенко, Г.М. Евелькин, Г.Н. Соколова, О.В. Терещенко. - Минск: Книжный дом, 2010. - 1312 с.

\title{
THE INFLUENCE OF MASS MEDIA ON THE FORMATION OF VALUE ORIENTATIONS OF KALININGRAD STUDENTS
}

\author{
M.V. Borisova, student \\ Kaliningrad State Technikal Universiry \\ e-mail: manyutta@mail.ru \\ N.N. Yarygin, Dr. Philos. Sciences, Assoc., \\ Kaliningrad State Technikal Universiry \\ e-mail: nikolaj.yarygin@klgtu.ru
}

The article analyzes the influence of mass media on the formation of value orientations of Kaliningrad students. The object of this study were full-time students. The purpose of the search sociological research was to identify the influence of various mass media on the formation of value orientations among students. To do this, the following tasks were set: determining the object of the study, compiling a questionnaire with questions, conducting a survey on the Internet, analyzing the results of the study. The method of available sampling was used to select respondents. The results of the study suggest that the most influential source of information for students are social networks, and the most unpopular are radio, television and the print press. The results obtained indicate that students are primarily interested in the dialogue of different points of view on the events taking place, the possibility of their independent analysis. Social networks meet these criteria.

Keywords: mass media, student youth, social networks 